\title{
Single dose trimethoprim for urinary tract infection
}

\author{
T NOLAN, ${ }^{*}$ L LUBITZ, $\dagger$ AND F OBERKLAID $\ddagger$ \\ ${ }^{*}$ Melbourne University Department of Paediatrics, and tDepartments of General Paediatrics and \\ $\ddagger$ Ambulatory Paediatrics, Royal Children’s Hospital, Parkville, Victoria, Australia
}

\begin{abstract}
SUMMARY A randomised clinical trial of single dose trimethoprim against a seven day course of co-trimoxazole (trimethoprim/sulphamethoxazole) for the treatment of uncomplicated urinary tract infection was carried out in 106 children aged between 2 and 16 years. Of the 50 children with confirmed urinary tract infections who were followed up 48 hours after treatment with a single dose of trimethoprim all were free of infection, whereas two of the 56 who received the course of co-trimoxazole $(4 \%)$ had persisting infections. At follow up after 10 days, however, significantly more of the group treated with trimethoprim had evidence of recurrent urinary tract infection compared with those who had received co-trimoxazole (10 of $44,23 \%$, compared with one of $46,2 \%)$. Of the recurrences in the trimethoprim group, six were asymptomatic.

We conclude that single dose trimethoprim is effective in clearing the urine of bacteria, but the risk of asymptomatic bacteriuria soon after treatment is high.
\end{abstract}

The use of a single dose or a single day of treatment for uncomplicated urinary tract infections in children has obvious attractions. ${ }^{1}$ These include improved compliance, more rapid resolution of symptoms, less risk of side effects, and reduced cost. ${ }^{2-4}$

Previous reports have suggested that a single dose is equally as effective as a longer course, but recent reappraisal has raised the question of inadequate sample size and the committing of the Type II error-the false assumption that the two treatments were equally effective when too few patients had been studied to be sure that even quite large differences had not been missed by chance. ${ }^{45}$ Moffat et al concluded after reviewing published clinical trials in children that there was insufficient evidence to advocate the use of short courses of treatment for urinary tract infections (Moffat $M$. Short course antibiotic therapy of urinary tract infections in children. Presented at the Annual Scientific Meeting of the Ambulatory Pediatric Association, Washington DC, May 1986)..$^{5}$ An additional problem is that early recurrence of infection may be more likely to occur after single dose treatment. ${ }^{6}$

Many antibiotics have been used in single dose treatment. Several trials have evaluated trimethoprim alone in the treatment of adult urinary tract infections, and concluded that it was as effective as co-trimoxazole (trimethoprim/sulphamethoxazole) when used in conventional courses. ${ }^{7-9}$ The rationale for the use of trimethoprim without sulphamethox- azole is the decreased risk of side effects, ${ }^{9}$ the reduced risk of the development of resistance, ${ }^{10}$ the reduced cost, and the elimination of an unnecessary drug from the regimen. ${ }^{11}$ No comparison that we know of has been made of trimethoprim and co-trimoxazole, nor has trimethoprim been used as a single dose in the treatment of uncomplicated urinary tract infections.

Our hypothesis was that in children and adolescents a single dose of trimethoprim was no less effective than a seven day course of co-trimoxazole in the early eradication of urinary tract infection, reducing the risk of early recurrence, and achieving early resolution of symptoms.

\section{Patients and methods}

Patients studied were outpatients presenting to the primary care or emergency departments of the Royal Children's Hospital. They were entered into the trial if they had a urinary tract infection on clinical assessment or microscopic examination of the urine, or both. Informed consent was obtained from the parents, and the following were excluded: those known or thought to be sensitive to sulphonamides, those with persistent vomiting or any other reason for not being able to tolerate oral treatment, those with ileostomies or ureterostomies, those already on antimicrobial treatment, and those aged less than 6 months.

A total of 254 patients were eligible, and were 
randomised in blocks within strata related to age (6-47 months, 48 months or older) and whether or not they had had previous urinary tract infections. Of these, $138(54 \%)$ were subsequently excluded because urinary tract infection was not confirmed by culture $(n=112)$, they failed to attend for follow up $(n=9)$, the organism cultured was resistant to trimethoprim or sulphamethoxazole $(n=8)$, they were entered into the study more than once $(n=7)$, or they were unable to take the drugs $(n=2)$. The characteristics of the remaining 116 patients are shown in table 1 . All but one patient in each group had symptoms including nausea, vomiting, urgency,

Table 1 Characteristics of patients

\begin{tabular}{lll}
\hline & $\begin{array}{l}\text { Single dose } \\
\text { trimethoprim } \\
(n=54)\end{array}$ & $\begin{array}{l}\text { Co-trimoxazole } \\
\text { twice daily } \\
\text { for seven days } \\
(n=62)\end{array}$ \\
\hline $\begin{array}{l}\text { Mean (SD) age (months) } \\
\text { Range }\end{array}$ & $81(33 \cdot 2)$ & $83(38 \cdot 1)$ \\
$\begin{array}{l}\text { No of girls (\%) } \\
\text { No of boys (\%) }\end{array}$ & $24-180$ & $28-188$ \\
$\begin{array}{l}\text { No (\%) who had had a previous } \\
\text { urinary tract infection }\end{array}$ & $68(89)$ & $52(84)$ \\
$\begin{array}{l}\text { No (\%) with abnormal } \\
\text { intravenous pyelogram }\end{array}$ & $18(33)$ & $10(16)$ \\
$\begin{array}{l}\text { No (\%) with abnormal } \\
\text { micturating cysto- }\end{array}$ & $6 / 52(12)$ & $13 / 60(22)$ \\
urethrogram & $16 / 40(40)$ & $15 / 43(35)$ \\
\hline
\end{tabular}

frequency, dysuria, haematuria, or abdominal, back, or loin pain. Almost half the children had at least one of the following symptoms or signs: fever greater than $38^{\circ} \mathrm{C}$, loin pain, back pain, or vomiting. More children receiving co-trimoxazole $(35,57 \%)$ had at least one of these signs than in the single dose group $(22,41 \%)$.

Confirmation of the diagnosis required a growth of more than $10^{8}$ colonies $/ 1$ in a midstream specimen of urine, or any growth from a suprapubic aspirate. Absence of infection was confirmed by a growth of less than $10^{7}$ colonies/ 1 from a midstream or bag specimen, or a sterile suprapubic aspirate. A mixed growth of organisms of $10^{7}$ colonies/l or more was considered to be indeterminate, as was a pure growth of $10^{7}$ colonies $/ 1$ or more from a bag specimen. Those with uncertain diagnoses were withdrawn from further analysis, and when these occurred at follow up they were recorded as missing values (fig 1). There were no significant differences between the groups in the type of organisms isolated at the time of entry into the study, the most common organisms being Escherichia coli (75\%), Klebsiella spp (5\%), and Proteus spp (3\%).

Trimethoprim was prepared as a powder from 300 $\mathrm{mg}$ tablets supplied by the manufacturer and given at the time of randomisation according to the regimen given in table 2 as a single dose in aqueous suspension under the supervision of nursing or pharmacy staff. A seven day course of cotrimoxazole was dispensed either as elixir or tablets

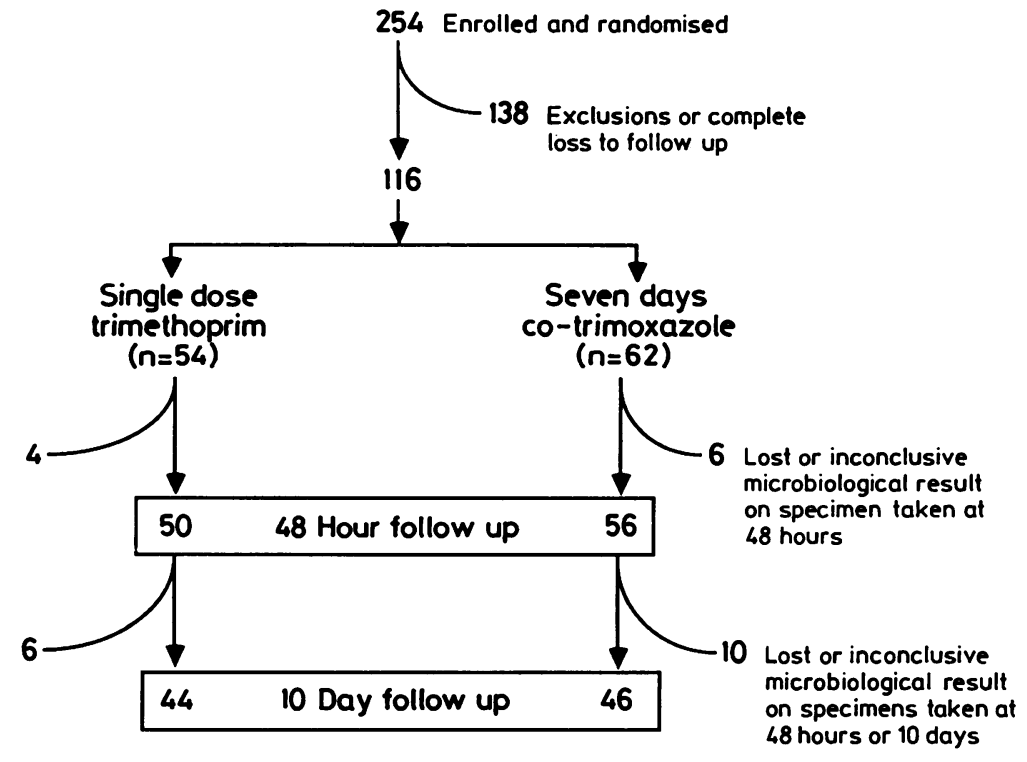

Fig 1 Study protocol. 
to be taken at home, and the parents were instructed to start the treatment immediately.

Patients were seen 48 hours and 10 days after randomisation and had further specimens of urine taken. All those who had not previously had a radiograph of the urinary tract had an intravenous pyelogram. In addition, those aged 7 years or younger had a micturating cystourethrogram one to three weeks after diagnosis. The study was carried out before renal ultrasonography had become a routine investigation.

Statistical analysis was by the Mantel-Haenszel test, and estimates of the risk ratio and its $95 \%$ confidence interval were calculated for infection rates in the single dose group compared with the seven day treatment. ${ }^{12} 13$ Assignment strata (age and past history or urinary tract infection) were used. The $95 \%$ confidence intervals were calculated for the difference in risk of recurrence.

\section{Results}

The results of treatment are shown in table 3 . Of the 50 patients with confirmed urinary tract infections who received a single dose of trimethoprim all were free of infection after $\mathbf{4 8}$ hours, whereas two of $\mathbf{5 6}$ (4\%) of those who were receiving a seven day course of co-trimoxazole still had evidence of infection $(\mathrm{p}=0.26,95 \%$ confidence interval on the difference $-9 \%$ to $1 \%)$. One of the two children

Table 2 Treatment regimens

\begin{tabular}{lcc}
\hline Age (years) & $\begin{array}{l}\text { Single dose } \\
\text { trimethoprim } \\
(\mathrm{mg})\end{array}$ & $\begin{array}{l}\text { Co-trimoxazole } \\
\text { twice daily for } \\
\text { seven days } \\
(\mathrm{mg})\end{array}$ \\
\hline$<2$ & 75 & $20 / 100$ \\
$2-5$ & 150 & $40 / 200$ \\
$6-11$ & 300 & $80 / 400$ \\
$>12$ & 450 & $160 / 800$ \\
\hline
\end{tabular}

with persistent infection had unilateral hydronephrosis. At the 10 day follow up of the patients in whom the presence or absence of urinary tract infection had been confirmed at 48 hours, however, 10 in the trimethoprim group (23\%) compared with only one in the co-trimoxazole group $(2 \%)$ had microbiological evidence of urinary tract infection $(p=0.004)$. Patients treated with a single dose of trimethoprim were 11.5 times more likely to have an early recurrence than those given a seven day course of co-trimoxazole (risk ratio $95 \%$ confidence interval $2 \cdot 2$ to $60 \cdot 3$ ). Neither age nor history of urinary tract infection had any effect on recurrence rates $(p=0 \cdot 31$, Breslow-Day test ${ }^{14}$ ).

Only four of the 10 patients in the trimethoprim group who had a recurrence of infection had any symptoms (table 4). Because it was not possible to type organisms it was not possible to differentiate relapse from reinfection. In only two patients, however (one from each group), was a different organism responsible for the recurrence. The only organism that was resistant to trimethoprim and sulphamethoxazole was the Streptococcus faecalis that was responsible for the recurrence in one patient who had received the seven day course. None of the patients who had recurrences had had loin tenderness or fever at the initial presentation.

Two thirds of the children who entered the study with confirmed urinary tract infections had not previously had infections, and eight of the 10 recurrences in the single dose group were in patients who had not previously had urinary tract infections. The child who had a recurrence in the cotrimoxazole group had had previous urinary tract infections.

More patients in the single dose group were symptom free or improved by the 48 hour follow up (47/50, 94\%, compared with $46 / 56,82 \% ; p=0.05)$. There was, however, no difference between the groups in those who were totally symptom free (61\% and $62 \%$, respectively, $p=0.92)$. Of the 10 children who had recurrences in the trimethoprim

Table 3 Results at follow up after 48 hours and 10 days. Results at 10 days refer only to subjects in whom the presence or absence of infection was confirmed at 48 hours

\begin{tabular}{|c|c|c|c|}
\hline Results & $\begin{array}{l}\text { Single dose } \\
\text { trimethoprim } \\
\text { No (\%) }\end{array}$ & $\begin{array}{l}\text { Co-trimoxazole twice } \\
\text { daily for seven days } \\
\text { No }(\%)\end{array}$ & p Value \\
\hline \multicolumn{4}{|l|}{48 hours: } \\
\hline Urinary tract infection & 0 & $2(4)$ & \\
\hline No urinary tract infection & $50(100)$ & $54(96)$ & $0 \cdot 26$ \\
\hline \multicolumn{4}{|l|}{10 Days: } \\
\hline Urinary tract infection & $10(23)$ & $1(2)$ & \\
\hline No urinary tract infection & 34 (77) & $45(98)$ & $0 \cdot 004^{*}$ \\
\hline
\end{tabular}

${ }^{*}$ Risk ratio $11 \cdot 5,95 \%$ confidence interval $2 \cdot 2$ to $60 \cdot 3$. 
Table 4 Details of patients with recurrent infections

\begin{tabular}{|c|c|c|c|c|c|c|c|}
\hline $\begin{array}{l}\text { Case } \\
\text { No }\end{array}$ & Sex & $\begin{array}{l}\text { Treatment } \\
\text { group }\end{array}$ & $\begin{array}{l}\text { Age } \\
\text { (years) }\end{array}$ & Symptoms & $\begin{array}{l}\text { Initial } \\
\text { organism } \\
\text { isolated }\end{array}$ & $\begin{array}{l}\text { Subsequent } \\
\text { organism } \\
\text { isolated }\end{array}$ & $\begin{array}{l}\text { Micturating } \\
\text { cystourethrogram }\end{array}$ \\
\hline 1 & Female & Trimethoprim & 7 & Symptom free & $E$ coli & $E$ coli & Not done \\
\hline 2 & Female & Trimethoprim & 5 & $\begin{array}{l}\text { Nausea, vomiting, urgency, } \\
\text { dysuria, frequency }\end{array}$ & E coli & E coli & Mild reflex \\
\hline 3 & Female & Trimethoprim & 8 & Symptom free & $E$ coli & $E$ coli & Normal \\
\hline 5 & Female & Trimethoprim & 8 & Symptom free & Citrobacter spp & Citrobacter spp & Normal \\
\hline 6 & Female & Trimethoprim & 4 & Nausea, vomiting & E coli & E coli & Normal \\
\hline 7 & Female & Trimethoprim & 8 & Urgency, dysuria, frequency & $\begin{array}{l}\text { Staphylococcus } \\
\text { saprophyticus }\end{array}$ & $\begin{array}{l}\text { Staphylococcus } \\
\text { saprophyticus }\end{array}$ & Not done \\
\hline 8 & Male & Trimethoprim & 11 & Symptom free & Proteus spp & Proteus spp & Normal \\
\hline 9 & Female & Trimethoprim & 6 & Symptom free & E coli & $E$ coli & Moderate reflux \\
\hline 10 & Female & Trimethoprim & 6 & Urgency, dysuria, frequency & $E$ coli & Proteus & Normal \\
\hline
\end{tabular}

group four still had symptoms at 48 hours, though in three these had improved. The one patient who had a recurrence in the co-trimoxazole group had no symptoms at 48 hours. The only adverse effect that was seen was at the 10 day follow up was in one child who had received co-trimoxazole who developed ulcers in the mouth.

\section{Discussion}

These results suggest that treatment of uncomplicated, symptomatic urinary tract infections in children by a single dose of trimethoprim effects a cure rate at 48 hours similar to that achieved with a conventional seven day course of co-trimoxazole, but that this is accompanied by an unacceptably high risk of local recurrence (often without symptoms). There is a higher rate of symptomatic improvement after $\mathbf{4 8}$ hours, but there is little overall difference in the rate of resolution of symptoms compared with the results after a conventional seven day course.

We do not know whether the higher risk of recurrence is caused by inadequately treated (perhaps parenchymal) infection, or reinfection with the same or a different organism. ${ }^{15}$ If the risk of recurrence is associated with a more established infection, a rapid diagnostic test to determine whether the patient has infection of the upper or lower renal tract could permit selective treatment with a single dose. Such a test, however, is not available. As none of the patients who had recurrences had both fever and loin tenderness at presentation one could speculate that reinfection rather than relapse was the most likely. Because of the unreliability of these clinical signs in localising the site of infection, however, firm conclusions cannot be drawn. It is noteworthy that the recurrences were mainly in children who had not previously had urinary tract infections, and who did not have structural abnormalities.

From these results it could be argued that trimethoprim without sulphamethoxazole is less effective than the combination. There were, however, no signs of urinary tract infection in patients in the trimethoprim group at 48 hours. In addition, it is doubtful whether synergy between trimethoprim and sulphamethoxazole is possible at the concentrations that can be achieved in urine. ${ }^{16}$ Because the inhibitory action of sulphamethoxazole is dependent on the size of the inoculum it takes several cycles of cell growth to exhaust the microbial folate supplies, whereas trimethoprim causes rapid deprivation of the thymidilate supply to the organisms leading to the abrupt termination of folate synthesis. It is therefore probable that if there is any therapeutic effect from a single dose of co-trimoxazole, it will be from the trimethoprim component. ${ }^{11} 17$

Because of a flaw in the design of the study it is difficult to interpret the differences in recurrence rates. Because the urine was cultured 48 hours and 10 days after treatment was started rather than after it had finished, we could have underestimated the recurrence rate in the co-trimoxazole group. The recurrence rate in the single dose group of $23 \%$, however, remains striking, and evidence from other trials suggests that an unbiased rate would still have been far below that in the single dose group. ${ }^{2} 6$ 18-21 The average recurrence rate in these six studies in patients given conventional courses was $9 \%$.

Further data extracted from these studies provide additional evidence that single dose treatment is more likely to be associated with early recurrence. Fig 2 shows the results of these trials plotted to show the confidence intervals of the difference in risk of 


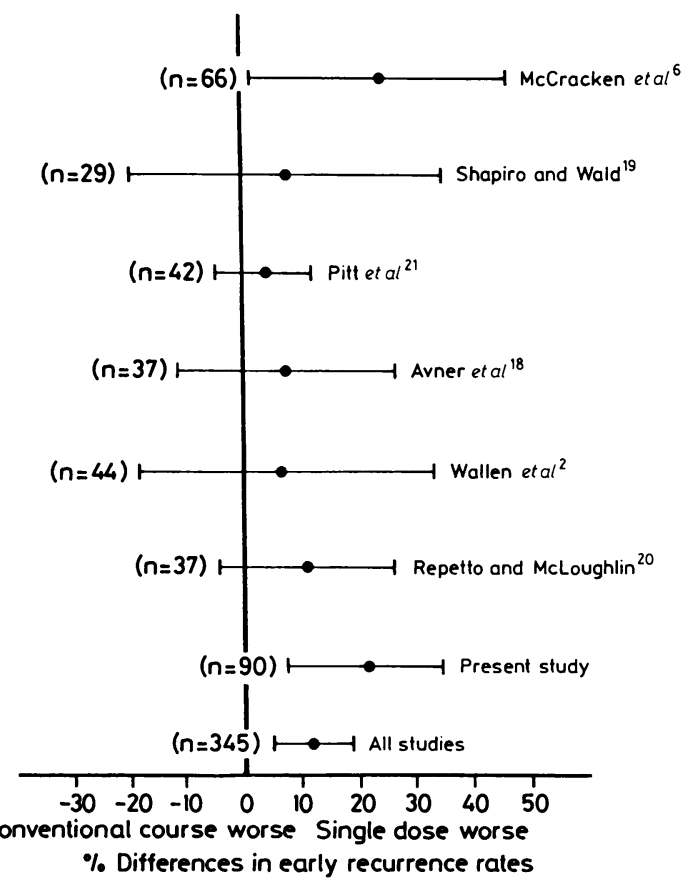

Fig 2 Differences in risk of early recurrence and their $95 \%$ confidence intervals from published clinical trials of single dose compared with conventional treatment.

recurrence between single dose and conventional treatment. The antibiotics used as single agents were: amoxycillin, ${ }^{18} 19$ a cephalosporin, ${ }^{6} 20$ amikacin, ${ }^{2}$ and co-trimoxazole. ${ }^{21}$ Rates of recurrence were assessed between five days and three months. Despite the diversity of antibiotics and lengths of follow up there is a striking unanimity of results in favour of the seven day course of antibiotic. Because of the small sample sizes, however, the results were significant only in the present study and in that of McCracken et al. ${ }^{6}$

The average difference in risk of recurrence between single dose and conventional treatment in these studies is $12 \%$ (95\% confidence interval of the true value $5 \%$ to $19 \%$; this is a sample size weighted calculation by the method of Gilbert $e t a l^{22}$ ). This means that for every 100 children treated with a single dose of an antibiotic for an uncomplicated urinary tract infection, between five and 19 would have an early recurrence of that infection that would not have occurred if they had had seven day courses.

Single dose treatment has been advocated in the past with the caveat that close monitoring of the response to treatment is important. ${ }^{23}$ The results of this study and others emphasise that the risk of asymptomatic recurrence should be borne in mind. We believe that there is now sufficient evidence to suggest that treatment of uncomplicated urinary tract infections with a single dose of an antibiotic should only be undertaken with caution, and with proper follow up. There is evidence in adult patients that failure of a single dose is more likely to result in failure of a subsequent course of treatment than if the initial failure had followed a course of treatment. ${ }^{24}$ Our results are mainly from young children (only three were over the age of 12) and it may be that the use of a single dose in children who are not at risk of acquiring renal scars would be appropriate; again, close follow up would be essential.

The combination of a high initial dose and a conventional course may effect more rapid symptomatic improvement without the risk of early recurrence of infection.

We thank Drs Peter Loughnan, Harley Powell, Jill Sewell, and Jan Cullen, together with an anonymous reviewer, for assistance and helpful criticism. We also thank the nurses in the department of ambulatory paediatrics for their enthusiastic cooperation, and Wellcome Australia for supplying the trimethoprim.

\section{References}

1 Ogra PL, Faden HS. Urinary tract infections in childhood: an update. J Pediatr 1985;106:1023-9.

2 Wallen MD, Zeller WP, Goessler M, Connor E, Yogev R. Single-dose amikacin treatment of first childhood $\mathrm{E}$ coli lower urinary tract infections. J Pediatr 1983;103:316-9.

${ }^{3}$ Fine JS, Jacobsen MS. Single-dose versus conventional therapy of urinary tract infections in female adolescents. Pediatrics 1985;75:916-20.

${ }^{4}$ Shapiro ED. Short course antimicrobial treatment or urinary tract infections in children: a critical analysis. Pediatr Infect Dis 1982;1:294-7.

5 Moffatt M, Embree J, Grimm MD and Law B. Short course antibiotic therapy for urinary tract infections in children: a methodological review of the literature. Am J Dis Child 1988;142:57-61.

${ }^{6}$ McCracken GH, Ginsburg CM, Namasonthi V, Petruska M. Evaluation of short-term antibiotic therapy in children with uncomplicated urinary tract infections. Pediatrics 1981;67: 796-801.

${ }^{7}$ Brumfitt W, Pursell R. Double-blind trial to compare ampicillin, cephalexin, cotrimoxazole and trimethoprim in the treatment of urinary infection. $\mathrm{Br}$ Med J 1972;ii:673-6.

${ }^{8}$ Koch UJ, Schumann KP, Kuchler R, Kewitz H. Efficacy of trimethoprim, sulfamethoxazole and the combination of both in acute urinary tract infections: clinical and pharmacokinetical studies. Chemotherapy 1973;19:314-21.

9 Lacey RW, Lord VL, Gunasekera HKW, Leiberman PJ, Luxton DEA. Comparison of trimethroprim alone with trimethoprim-sulfamethoxazole in the treatment of respiratory and urinary infections with particular reference to selection of trimethoprim resistance. Lancet 1980;i:1270-3.

10 Anonymous. Bacterial resistance to trimethoprim. [Editorial.] Br Med J 1980;ii:571-2.

11 Anderson JD, Lacey RW, Lewis EL, Sellin MA. Failure to demonstrate an advantage in combining sulfamethoxazole with 


\section{Nolan, Lubitz, and Oberklaid}

trimethoprim in an experimental model of urinary infection. $J$ Clin Pathol 1974;27:619-22.

12 Mantel N, Haenszel W. Statistical aspects of the analysis of data from retrospective studies of disease. JNCI 1959;22:719-48.

13 Green SB, Byar DP. The effect of stratified randomization on size and power of statistical tests in clinical trials. J Chronic Dis 1978;31:445-54.

14 Breslow NE, Day NE. Statistical methods in cancer research. Vol 1. The analysis of case control studies. Lyon: International Agency for Research on Cancer, 1980.

15 Tolkoff-Rubin NE, Rubin RH. Single dose treatment of acute uncomplicated infections defined by the antibody-coated bacteria assay. In: Bailey RR, ed. Single dose therapy of urinary tract infection. Sydney: ADIS Health Science Press, 1983:42-52.

16 Greenwood D. Relevance of in vitro synergy to therapy: does synergy between diaminopyridines and sulfonamides operate at concentrations achievable in the urine? $J$ Antimicrob Chemother 1979;5(suppl B):85-9.

17 O'Grady F. Single dose treatment of urinary tract infection: a microbiologist's view. In: Bailey RR, ed. Single dose therapy of urinary tract infection. Sydney: ADIS Health Science Press, 1983:79-81.

18 Avner Ed, Inglefinger JR, Herrin JT, et al. Single-dose amoxicillin therapy of uncomplicated pediatric urinary tract infections. J Pediatr 1983;102:623-7.

${ }^{19}$ Shapiro ED, Wald ER. Single-dose amoxicillin treatment of urinary tract infections. J Pediatr 1981;99:989-92.

${ }^{20}$ Repetto HA, MacLoughlin GJF. Single dose cefotaxime in the treatment of urinary tract infections in children: a randomised clinical trial. J Antimicrob Chemother 1984;14(suppl B):307-10.

${ }^{21}$ Pitt WR, Dyer SA, McNee JL, Burke JR. Single dose trimethoprim-sulfamethoxazole treatment of symptomatic urinary infection. Arch Dis Child 1982;57:229-31.

22 Gilbert JP, McPeek B, Mosteller F. Progress in surgery and anesthesia: benefits and risks of innovative therapy. In Bunker J, ed. Costs, risks and benefits of surgery. New York: Oxford, 1977.

${ }^{23}$ Smith AL. Editorial. Pediatr Alert 1982;7:4

${ }^{24}$ Rubin RH, Fang LST, Jones SR, et al. Single dose amoxycillin therapy for urinary tract infection. JAMA 1980;244:561-564.

Correspondence to Dr T Nolan, University of Melbourne Department of Paediatrics, Royal Children's Hospital, Parkville, Victoria 3052, Australia.

Accepted 26 August 1988 